\title{
Web-Based Learning: A Bridge to Meet the Needs of Canadian Nurses for Doctoral Education
}

Sue Kurucz, Lori Rietze, Angie Lim, \& Mindy Swamy

University of Victoria

\begin{abstract}
Canada does not have enough nurses with doctoral degrees. Such nurses fill important roles as researchers, educators, leaders, and clinicians. While a growing number of Canadian universities offer doctorate degrees in nursing, most institutions have only traditional on-campus programs, posing barriers for nurses who reside in places geographically distant from those institutions or who require more flexibility in their education. We describe our experiences as the inaugural cohort of the doctoral program by distributed learning at the University of Victoria School of Nursing. Since 2011, we have used a variety of electronic modalities and participated in several very short on-site intensives. Our experience indicates that distributive learning modalities improve access and deliver academically rigorous programs.
\end{abstract}

\section{Résumé}

Au Canada, il existe présentement une pénurie de personnel infirmier détenant un doctorat. De tels infirmiers assument d'importantes fonctions à titre de chercheurs, d'éducateurs, d'administrateurs et de cliniciens. Tandis qu'un nombre croissant d'universités canadiennes offrent des programmes de doctorat en sciences infirmières, la plupart des établissements n'offrent ces programmes que de manière traditionnelle, c'est-à-dire que les étudiants doivent se rendre à l'université pour assister aux cours afin de recevoir l'enseignement. Ce type de programmes constitue un obstacle pour les étudiants des régions éloignées qui ont besoin de plus de flexibilité pour y accéder. Le présent article décrit notre expérience à titre de première cohorte 
du programme de doctorat en sciences infirmières de l'École des sciences infirmières de l'Université de Victoria, offert selon ce modèle d'apprentissage échelonné. Depuis 2011, sur le site géographique de l'université, à Victoria, nous avons utilisé une variété de moyens pédagogiques alliant technologie et courts stages intensifs. Notre expérience démontre que les modèles d'apprentissage échelonné améliorent l'accès aux programmes académiques de haute qualité et en rehaussent la qualité académique.

Nursing education faces a pending crisis within the next ten years. The Canadian Nurses Association (CNA) and the Canadian Association of Schools of Nursing (CASN) report that the number of doctoral graduates is insufficient to meet demand (CASN, 2010; CNA \& CASN, 2012a; 2012b). High numbers of current faculty members are approaching the age of retirement, and few are under 40 years of age (CASN 2008; 2010). While nurses with $\mathrm{PhDs}$ are needed to fill faculty positions, they are also in demand for research and administrative roles in an increasingly complex healthcare environment (Cleary, Hunt, \& Jackson, 2011). There are currently 15 nursing PhD programs in Canada. Although 25 percent of these programs utilize some components of distance education (CNA \& CASN, 2012b), 85 percent require full-time residency (CASN, 2010).

Distance learning brings together individuals who are geographically dispersed using computers and telecommunication technologies for asynchronous and synchronous learning (Belanger \& Jordon, 2000). In asynchronous learning, online lecture notes or discussion boards are used to promote learning at one's own pace (Belanger \& Jordon, 2000). Synchronous learning, on the other hand, is real-time learning in which live discussions or teaching occur by means of web-hosted software programs such as Blackboard Collaborate, Elluminate Live!, or Bluejeans (Belanger \& Jordon, 2000). Distributed learning incorporates all aspects of distance learning, both synchronous and asynchronous modalities, thereby allowing learners to learn at their own pace, independent of geographic location (Belanger \& Jordon, 2000). In contrast, programs with a full-time residency requirement limit the accessibility of doctoral education to nurses who reside within driving distance of the school offering the program.

In response to the looming shortage of PhD-prepared nurses, the School of Nursing at the University of Victoria (UVic) initiated a distributed option doctoral program in September 2011. We, the authors, form the first cohort of the program. We have now completed the first two years of this program. Our aim in this paper is to describe our experiences as distributive learning doctoral students within the context of higher education in Canada. We recognize that changes will undoubtedly occur in the structure of the program. Nonetheless, we feel that as society embraces more technology, our early experiences offer the reader an opportunity to gain understanding of this novel and important innovation in Canadian nursing education at the doctoral level.

\section{Context of the Canadian PhD Nursing Landscape}

To understand the current state of doctoral studies for nurses in Canada, it helps to take a historical glance at nursing's educational history. According to Wood, Giovannetti, and Ross-Kerr (2004), nursing's important contribution to the community was recog- 
nized during the Second World War, with post-war changes bringing graduate education into nursing. The University of Western Ontario (UWO) (1959) and McGill University (1961) were the first to introduce master's-level programs into nursing education in Canada. As nurses began to express a desire to both create and utilize nursing research, there was a developing need to discuss and share research methodologies and findings among colleagues. Against this backdrop, the first nursing research conference was hosted by the Canadian Nurses Association (CNA) in Ottawa in 1971, and since then, the CNA has played an integral role in developing PhD nursing programs in Canada. During the 1978 CNA biennial conference, a motion called for the CNA to mobilize necessary resources for the immediate development and initiation of doctoral nursing programs in Canada (Wood et al., 2004). In 1979, the CNA operationalized this mandate by developing Operation Bootstrap to provide a blueprint for $\mathrm{PhD}$ programs in Canada. In turn, the first Canadian doctoral program in nursing opened at the University of Alberta in 1991.

According to CASN's Environmental Scan on Doctoral Programs (2010) and the CNA/CASN document entitled Registered Nurses Education in Canada Statistics 201O2011 (2012b), there were 480 students enrolled in PhD nursing programs in Canada in 2011. This represents a significant rise in enrolment from 2008 and 2009, in which there were 401 and 409 enrolees, respectively. Other data support that the number of graduates from Canadian doctoral nursing programs has increased by $15.6 \%$ from 2010 (77 graduates) to 2011 (89 graduates) (CNA \& CASN, 2012b).

Yet even with the increase in doctoral graduates, CNA and CASN (2012b) and the Canadian Health Services Research Foundation (CHSRF) (2008) anticipate that there is an imminent shortage of qualified nursing faculty, given the current level of enrolment in bachelor of nursing programs. In 2011, 7,554 faculty members were employed by schools of nursing where $30.7 \%$ were tenured or tenure-track (also known as permanent faculty), and $56.5 \%$ of these permanent faculty members were 50 years of age or older (CNA \& CASN, 2012b). Consequently, it is anticipated that there will be a substantial number of nursing faculty retiring in the near future with few qualified nurses to replace this loss. To further press this point, in the 2010 report by CNA and CASN (2012b), it was stated that 76 full-time faculty positions in Canadian schools of nursing were already unfilled.

In addition to filling faculty roles, nurses with doctoral training are needed for leadership roles in health organizations, government, and industry. It is difficult to establish the numbers of PhD-prepared nurses who occupy these positions or what the demand will be in the future. We feel that these opportunities will grow and offer a competitive career option for doctoral graduates. This will increase the overall number of PhD-prepared nurses needed in Canada and could potentially magnify shortages in academia.

\section{The University of Victoria Distributed Learning Program}

In line with the university's strategic goal to increase accessibility to education for rural populations, the UVic School of Nursing has offered distance education at the undergraduate and master's levels since 1980 (D. Walton, personal communication, October 22, 2012). In 2011, UVic began offering their $\mathrm{PhD}$ in nursing program through distributive learning. Planned as a four-year program, this curriculum prepares students to contribute to nursing disciplinary growth in research, education, practice, and administra- 
tion. Students are required to enroll in core courses (philosophy, epistemology, research methods, seminars) as well as elective courses, all of which are offered through a combination of synchronous and asynchronous modalities. The distributive option requires that in addition to required courses, students attend two 10-day onsite residency periods during the first year; students are also expected to be on campus for their oral candidacy defense, research proposal defense, and dissertation defense.

\section{Demographics of Doctoral Nursing Students and the First Cohort}

Data from the United Kingdom (McKenna, 2005), the United States (McEwen \& Bechtel, 2000), and Australia (Jackson and Cleary, 2011) show that doctoral students in nursing are older and more likely to be working as established professionals than the general population of doctoral students as a whole. Although no Canadian data could be found, our own observation is that these traits also follow for Canadian students.

Our cohort stands out demographically from the population of all Canadian doctoral students. When compared to the national survey of earned graduates (King, Eisl-Culkin, and Desjardins, 2008), our cohort is older and we have a longer period between our undergraduate education and our doctorate degrees. More students from this cohort are married, have children in the home, and have external work commitments than the average Canadian doctoral student (see Table 1).

Table 1

Comparison Between 2011 UVic PhD Nursing Cohort and All Canadian PhD Graduates

\begin{tabular}{|c|c|c|}
\hline & $\begin{array}{l}\text { UVic PhD Nursing } \\
2011 \text { Entry Cohort } \\
(\mathrm{n}=4)\end{array}$ & $\begin{array}{l}\text { Canadian PhD Graduates } \\
\text { (All Disciplines) }^{\mathrm{a}} \\
\text { (n=3972) }^{\text {n }}\end{array}$ \\
\hline Age at PhD Completion & 40 years (anticipated) & 33 years \\
\hline $\begin{array}{l}\text { Time from Commencing Un- } \\
\text { dergraduate Studies to PhD } \\
\text { Completion }\end{array}$ & 22 years (anticipated) & 13 years \\
\hline Married/Common-Law & $100 \%$ & $70 \%$ \\
\hline Children in Home & $\begin{array}{l}75 \% \\
\text { (50\% with children } \\
<5 \text { years old) }\end{array}$ & $36 \%$ \\
\hline $\begin{array}{l}\text { Work During Studies (Apart } \\
\text { from Fellowship or Intern- } \\
\text { ship) }\end{array}$ & $\begin{array}{l}100 \% \\
\text { (75\% full-time) }\end{array}$ & $22 \%$ \\
\hline
\end{tabular}

Note.

a Data from King et al. (2008)

Only one of the four of us lives close to an institution that grants doctoral degrees in nursing. It would take relocation or a significant commute for the other three to engage in doctoral studies in an onsite program.

We believe that these demographic and geographic attributes make a traditional onsite doctoral program inaccessible for many nurses who have the desire and aptitude to complete doctoral studies. It is unlikely that any of us would have been able to engage in our 
studies at this point in our lives without significant hardship to our families and careers. In a time when doctorally educated nurses are needed, the existence of a program with innovative delivery methods makes doctoral studies accessible to nurses who have young children and wish to maintain employment during their education.

As a mother of three children under the age of seven, I also occupy a tenure-track position at a Canadian university located in a rural area of Northern Ontario. As such, the nearest onsite $\mathrm{PhD}$ program in nursing is located more than five hours away. Enrolment in the University of Victoria's distributive option has allowed me to learn from world-renowned scholars while maintaining a level of stability for my family and employer.

\section{Benefits of a Distributed Learning PhD Program}

The University of Victoria has a vision of using innovative educational technologies to bring people together in learning communities so that teaching, supervision, and research can be conducted among scholars who are geographically distant. Based on our experiences, the benefits of a distributive $\mathrm{PhD}$ program are profound.

First, the UVic School of Nursing distributive PhD program provides both flexibility and accessibility through the use of innovative technology. Electronic platforms such as Elluminate Live! and Moodle enable course discussions both asynchronously and synchronously. Students can collaborate with peers and access multiple resources asynchronously during self-determined study times and synchronously during pre-determined online meeting times for seminars and lectures. Second, we are able to manage the multiple demands of family and work schedules by facilitating access to learning outside of set class hours and without the constraints of work-day hours or of differing times zones. Third, as students of the distributive delivery, we are able to continue our nursing practice, and this benefits our doctoral work in two particular ways: by minimizing financial barriers and by grounding our research in current clinical practice. Fourth, we have found that online modalities facilitated by emerging technologies have enabled increased access to a wide variety of faculty members at their home universities, as well as national and international nurse researchers. Fifth, developing a familiarity with various online modalities has increased our capacity to use novel pedagogical technologies in our own research and teaching careers. Interestingly, other nursing students in a distance program have reported similar experiences (Place, MacLeod, Adamack, \& Lindsey, 2012).

As a manager working in a program that provides services to older adults in my community, immersion in the literature, philosophical awareness of world-views, and current practice enable me to influence best practices in my own workplace and identify areas for research that are timely and relevant.

The opportunity to study at a distance has permitted me to continue working in my specialty area of nursing, thereby allowing for continued access to the target population for my dissertation research. 


\section{Challenges of a Distributed Learning PhD Program}

It has been argued that there are issues and challenges associated with distance and distributive learning models. Bruce et al. (2008) prompt one to consider challenges that are common for students who are studying at a distance. For example, identifying a supervisor and developing or maintaining a supervisory relationship may be difficult with limited face-to-face interaction, and analyzing research data under the guidance of a supervisor or committee member may be more complex if they live a substantial distance away. Owen, Bantum, and Golant (2009) reinforce this concern, citing support group facilitators who refer to challenges in "work[ing] around" the distance that is inherent in distance education. Yet despite these challenges, with the dedication and support of faculty, students have been able to develop rich and diverse committees with networking, suggestions, and referrals from faculty members.

I was connected with a potential committee member through an email introduction from a faculty member mentor who had met a social worker specializing in my area of interest at a conference in Vancouver.

As a student of the distributive program, I feel that the onsite sessions during the first year of the program were essential in building a relationship with my colleagues and assessing fit between my interests and that of my supervisor. In fact, during this week, I changed interim supervisors after a Nursing PhD wine and cheese event to better meet my goals in the program.

Based on our experiences in a distributed $\mathrm{PhD}$ in nursing program, we have also identified challenges related to technology and pedagogy, financial constraints, funding restrictions, and limited personal contact. At times, during online synchronous classes, technological glitches led to weak connections and time lags, which greatly impaired our ability to communicate. Some software-specific limitations are worth mentioning. Using Elluminate Live!, we experienced delays in face-to-face communication, microphone feedback sounds, and limitations in the number of participants who could be displayed visually. Using Skype, we experienced bandwidth limitations when logged in with multiple users, resulting in lag time and delayed interaction. Further, we found that when inviting guest speakers or faculty members who were not familiar with the software, a learning period was required before the session could begin. Due to the technological difficulties inherent in online course work, we greatly relied on information technology experts to provide support. We also found that using software to facilitate learning created an overreliance on text and presentations, with diminished opportunities for free-flowing discussion.

In addition to technological challenges, some potential sources of graduate student funding were inaccessible to students residing outside the province of British Columbia. One student who, with the support of her supervisor, applied for a graduate student position with a research and leadership group discovered after the application had been submitted and accepted that the group was funded by a grant that supported nursing research capacity in British Columbia only. Although the student was a forerunner for the position, her application had to be withdrawn. 
Another financial concern resulted from onsite residency expenses and heightened computer hardware and/or software requirements that were the sole responsibility of the student. Some examples of expenses incurred during onsite residency periods were related to lodging, meals, and transportation, such as flights, ferries, or buses, in addition to the lost time at our places of employment.

Finally, we experienced some limitations pertaining to personal contact with the students of our cohort, our professors, and our supervisors. In part, limitations in personal synchronous contact were due to time zone differences (there is a three-hour difference between Ontario and British Columbia), but we also found that the informal brainstorming or networking that sometimes occurs among students or between students and faculty in a university's hallways or coffeehouses was not possible. As a result, we felt isolated at times from one another and from learning opportunities that were offered onsite only, such as presentations given by guest speakers, when accessibility by teleconference was not available. This sense of isolation was also reported by Halter, Kleiner, and Hess (2006) in a study of distance doctoral education students in the USA. As one might expect, interpersonal learning and collaborative work between the students in our cohort was often challenging, and mentorship opportunities arising from the student/professor relationship were sometimes limited.

Thus, offsite doctoral education remains challenging and students must work towards building relationships with faculty and colleagues by identifying opportunities for collaborative work and other mentorship or networking prospects. For example, some of the students in our cohort are members of an online, synchronous, grounded theory research group originating at the University of Victoria that meets biweekly, and others enroll in or audit courses that are accessible to distance students using Elluminate Live! or Bluejeans. These groups provide additional learning, networking, and mentorship within and between PhD students at UVic. To build student/professor relationships, all students participated in directed studies or research internship courses with UVic faculty members, which provided one-on-one synchronous and asynchronous mentorship in a chosen area, such as grounded theory, ethnography, and statistics. We also initiated our own synchronous online meeting times as a cohort outside of required course meeting times to discuss ideas, collaborate on research projects, share knowledge and resources, and provide support and encouragement with our continued studies and preparation for candidacy.

It is often said that obtaining a $\mathrm{PhD}$ is a lonely road, but I think it is magnified for us. Not only do we spend our learning time alone in our home offices, but we don't get the opportunity to socialize and debrief with others in the same situation. Technology just doesn't allow us to chat in the same way we would in the hallway or a coffee shop. Our learning feels like it is goal- or task-oriented rather than organic.

\section{Outcomes}

Understandably, there is a concerted interest in and call for measurement of the outcomes of online and distance learning as compared to those of traditional modalities (Allen \& Seaman, 2006; US Department of Education, 2012). In their meta-analysis of comparative distance education literature from 1985 to 2002, Bernard et al. (2004) concluded that it is pedagogical excellence that determines the effectiveness of distance edu- 
cation, not the technologies or programs themselves. We are curious to know whether the distributive option for the doctoral nursing program at UVic will produce the same calibre of graduates as the traditional offering.

Twenty-four months into the program, we are just now completing our coursework and preparing for the candidacy exams that will determine our readiness to move forward to planning and conducting our dissertation research. We have not yet faced the major milestones of the doctorate journey that might measure our calibre or success; the outcomes of our candidacy examinations will be telling. They will establish whether students can, by distance, gain comprehensive knowledge of the discipline of nursing, their substantive areas of focus, and their chosen research methodology.

Anecdotal input from our professors is positive. They have reported that our distributed learning cohort is progressing at the same rate as previous cohorts. We have all received positive grades and evaluations from our professors, which suggests that we are meeting their expectations. These professors have all previously taught in the onsite $\mathrm{PhD}$ nursing program.

As a cohort, we have learned to work closely together in several extracurricular academic pursuits. On reflection, we note collaborative and learning strategies that we have found useful in overcoming technological challenges, pedagogical limitations, and isolation. To be consistent with constructivist epistemology in the assumption that knowledge is constructed and transformed by ourselves, we respect each other's individual abilities and contributions and share the authority and responsibility for group actions and outcomes. To do this, we have used the following academic collaborative and learning strategies: 1) maintaining strategies for peer mentoring and anticipatory guidance, 2) continuing our commitment to learning and knowledge construction, 3) using reliable software to communicate and outline tasks to be completed, and 4) attending on-campus UVic School of Nursing conferences, research groups, and research seminars whenever possible. To date, we have presented at two major conferences and are co-authoring two manuscripts for publication. Our professors report that no previous cohort has ever engaged in such pursuits as a team. While this may have occurred in a traditional learning setting, we believe that our ability to work productively together both synchronously and asynchronously by distance has facilitated this outcome, and we also think that as distance students, we try to make a significant effort to collaborate outside of coursework in order to continue learning and peer mentoring. Critical questions that could guide future work related to distributed learning might be: How can we best prepare distributed PhD students for study? How can we best support PhD students at a distance? How can we foster the supervisory relationship at a distance?

\section{Summary}

Distributed modalities create opportunities for nurses to have access to doctoral education despite their geographic location. Increasing the numbers of PhD-prepared nurses requires innovation in education. Our experience in the UVic distributive PhD nursing program provides an example of distributed learning as a viable option for doctoral education-an option that aims to address both the impending shortage and the promises of innovative educational formats for higher education. Future research may explore ways in which doctoral students can be supported when studying at a distance. We look forward to reporting on our progress as we move through the program. 


\section{References}

Allen, I. E., \& Seaman, J. (2006). Making the grade: Online education in the United States. Newburyport, MA: Sloan Consortium.

Anderson, C. A. (2000). Current strengths and limitations of doctoral education in nursing: Are we prepared for the future? Journal of Professional Nursing, 16(4), 191200. doi:10.1053/jpnu.2000.7830

Belanger, F., \& Jordan, D. (Eds.). (2000). Evaluation and implementation of distance learning: Technologies, tools and techniques. Hershey, PA: Idea Group Publishing.

Bernard, R. M., Abrami, P. C., Lou, Y., Borokhovski, E., Wade, A., Wozney, L., Wallet, P. A., et al. (2004). How does distance education compare with classroom instruction? A meta-analysis of the empirical literature. Review of Educational Research, 74(3), 379439. doi:10.3102/00346543074003379

Bruce, A., Stajduhar, K., Molzahn, A., MacDonald, M., Starzomski, R., \& Brown, M. (2008). Nursing graduate supervision of theses and projects at a distance: Issues and challenges. International Journal of Nursing Education Scholarship, 5(1), article 43. doi:10.2202/1548-923X.1587

Canadian Association of Schools of Nursing. (2008). Nursing education in Canada statistics: 2006-2007. Retrieved from http://www.casn.ca/vm/newvisual/ attachments/856/Media/StudentandFacultySurveyInfofor20062007report.pdf

Canadian Association of Schools of Nursing. (2010). Environmental scan on doctoral programs: Summary report. Retrieved from http://www.casn.ca/vm/newvisual/ attachments/856/Media/MicrosoftWordEScanDoctoralprogramsFinalKGCBSB.pdf

Canadian Health Services Research Foundation. (2008). Nursing research in Canada: A status report. Retrieved from www.cfhi-fcass.ca/Migrated/PDF/ NursingResCapFinalReport_ENG_Finalb.pdf

Canadian Nurses Association. (2003). Joint position statement: Doctoral preparation in nursing. Ottawa, Canada: CNA. Retrieved from http://www.cna-aiic.ca/ /media/cna/ page\%20content/pdf\%20en/2013/o8/29/19/14/ps75_doctoral_preparation_e.pdf

Canadian Nurses Association \& Canadian Association of Schools of Nursing. (2012a). Registered nurses education in Canada statistics 2009-2010. Ottawa, Canada: CNA. Retrieved from http://www.cna-aiic.ca/ /media/cna/page\%20content/pdf\%20 en/2013/07/26/10/41/education_statistics_report_2009_2010_e.pdf

Canadian Nurses Association \& Canadian Association of Schools of Nursing. (2012b). Registered nurses education in Canada statistics 2010-2011. Ottawa, Canada: CNA. Retrieved from http://www.cna-aiic.ca/ /media/cna/page\%20content/pdf\%20 en/2013/07/26/11/08/nsfs_report_2010-2011_e.pdf

Cleary, M., Hunt, G. E., \& Jackson, D. (2011). Demystifying PhDs: A review of doctorate programs designed to fulfill the needs of the next generation of nursing professionals. Contemporary Nurse, 39(2), 273-280. doi:10.5172/conu.2011.273 
Halter, M. J., Kleiner, C., \& Hess, R. F. (2006). The experience of nursing students in an online doctoral program in nursing: A phenomenological study. International Journal of Nursing Studies, 43(1), 99-105. doi:10.1016/j.ijnurstu.2005.03.001

Jackson, D., \& Cleary, M. (2011). Practical advice to support mid-career doctoral students in nursing: Some considerations for academic supervisors. Contemporary Nurse, 38(1/2), 171-179. doi:10.5172/conu.2011.38.1-2.171

King, D., Eisl-Culkin, J., \& Desjardins, L. (2008). Doctorate education in Canada: Findings from the survey of earned doctorates. Statistics Canada Catalogue No: 81-595M. Ottawa, Canada: Statistics Canada.

McEwen, M., \& Bechtel, G. A. (2000). Characteristics of nursing doctoral programs in the United States. Journal of Professional Nursing, 16(5), 282-292. doi:10.1053/ jpnu.2000.9458

McKenna, H. (2005). Doctoral education: Some treasonable thoughts. International Journal of Nursing Studies, 42(3), 245-246. doi:10.1016/j.ijnurstu.2005.01.001

Milstead, J. A., \& Nelson, R. (1998). Preparation for an online asynchronous university doctoral course: Lessons learned. Computers in Nursing, 16(5), 247-258. Available from http://journals.lww.com/cinjournal

Owen, J. E., Bantum, E. O., \& Golant, M. (2009). Benefits and challenges experienced by professional facilitators of online support groups for cancer survivors. PsychoOncology, 18(2), 144-155. doi:10.1002/pon.1374

Place, J., MacLeod, M., John, N., Adamack, M., \& Lindsey, A. E. (2012). "Finding my own time": Examining the spatially produced experiences of rural RNs in the rural nursing certificate program. Nurse Education Today, 32(5), 581-587. doi:10.1016/j. nedt.2011.07.004

University of Victoria.(2012).Avisionfor the future: Building on excellence: A strategic plan for the University of Victoria. Retrieved from http://web.uvic.ca/strategicplan

US Department of Education, Office of Education Technology. (2012). Understanding the implications of online learning for educational productivity. Retrieved from http:// www2.ed.gov/about/offices/list/os/technology/implications-online-learning.pdf

Wood, M., Giovannetti, P., \& Ross-Kerr, J. C. (2004). The Canadian PhD in nursing: A discussion paper. Written for the Canadian Association of Schools of Nursing. Retrieved from http://www.casn.ca/vm/newvisual/attachments/856/Media/ THECANADIANPHDINNURSING.pdf

\section{Acknowledgements}

The authors wish to thank Betty Davies and Anne Bruce, as well as the two anonymous reviewers, for comments and feedback on earlier versions of this paper. We also wish to thank all the professors who are accompanying us on the adventure of obtaining doctoral degrees via distributed education. 


\section{Contact Information}

Sue Kurucz

School of Nursing

University of Victoria

skurucz@uvic.ca

Sue Kurucz is a Manager on Vancouver Island, BC, working in Continuing Health Services. She is also a student in the nursing PhD program at the University of Victoria. She has a keen interest in residential care, particularly the optimal care model for those with moderate to advanced dementia.

Angie Lim is a Professor of Nursing at George Brown College, a nurse on the transplant unit at Sick Kids Hospital in Toronto, and a PhD student in nursing at the University of Victoria. She is interested in the process of transition from paediatric to adult care for adolescent transplant recipients.

Lori Rietze is an Assistant Professor at Laurentian University and a PhD student in nursing at the University of Victoria. She is interested in the involvement of registered nurses in end-of-life care in non-palliative acute-care settings and in the particular needs of marginalized and vulnerable populations.

Mindy Swamy is a PhD student in nursing at the University of Victoria. Her research interests centre around primary health care, people's experiences of health and illness, and women's health. 